\title{
Retraction notice to: "Adaptive algorithm for wireless data transmission (including images) based on SISO system and OFDM technique"
}

Valentin Fedosov, Andrey Legin and Anna Lomakina

Southern Federal University, 344006 Rostov-on-Don, Russia

At the request of the Authors, the following article has been retracted from MATEC Web of Conferences Volume 226 for the following reason:

This article was sent simultaneously by mistake to two different journals, MATEC Web of Conferences and another journal, generating an ethical problem of double publication. The organizers and the authors apologize for the mistake that is more related to an administrative error than a deliberate misconduct. The Editorial Board of MATEC Web of Conferences and EDP Sciences have agreed to retract the article.

Refers to RETRACTED: Adaptive algorithm for wireless data transmission (including images) based on SISO system and OFDM technique, Valentin Fedosov, Andrey Legin and Anna Lomakina, published online on 07 November 2018

Original article: MATEC Web of Conferences 226, 05008 (2018), https://doi.org/10.1051/matecconf/201822605008

https://www.matec-

conferences.org/articles/matecconf/abs/2018/85/matecconf_dts2018_05008/matecconf_dts2018_05008.html 